\title{
Changes in the Retinal Vascular Network Morphology (Diameter and Tortuosity) after Administration of Intravitreal Bevacizumab in a Patient with Ischaemic Branch Retinal Vein Occlusion
}

\author{
Aditya Kelkar Rachana Shah Jai Kelkar Shreekant Kelkar \\ Shilpa Bhirud Poonam Gandhi
}

National Institute of Ophthalmology, Pune, India

\section{Key Words}

Bevacizumab · Branch retinal vein occlusion $\cdot$ Retinal vessel morphology

\begin{abstract}
We report a case of transient reduction in the diameter and tortuosity of an occluded vessel after intravitreal administration of $1.25 \mathrm{mg}(0.05 \mathrm{ml})$ bevacizumab in a patient with ischaemic branch retinal vein occlusion. A 64-year-old hypertensive female presented with chief complaints of reduced vision in her right eye for 3 months. Her vision in the right eye was evaluated as counting fingers at $2 \mathrm{~m}$. Fundus examination revealed superotemporal branch retinal vein occlusion. On fluorescein angiography, in the superotemporal quadrant, there was hyperfluorescence that increased in size and intensity in the late phase, suggestive of a leaking neovascular frond. In addition, there was capillary non-perfusion in the adjacent area. The patient was administered $1.25 \mathrm{mg}(0.05 \mathrm{ml})$ of bevacizumab intravitreally in her right eye, under all aseptic precautions. After 1 week, her right eye fundus showed regression of neovascularisation. Fluorescein angiography also demonstrated regression of neovascularisation in addition to a decrease in the diameter and tortuosity of the retinal vessel.
\end{abstract}

(C) 2014 S. Karger AG, Basel

Dr. Aditya Kelkar

National Institute of Ophthalmology

1187/30, Off Ghole Road, Near Phule Museum

Shivajinagar, Pune 411005 (India)

E-Mail adityapune4@gmail.com 
Kelkar et al.: Changes in Retinal Vascular Network after Intravitreal Bevacizumab

\section{Introduction}

Anti-vascular endothelial growth factor (anti-VEGF) treatment has added a new dimension to the management of ischaemic ocular conditions. Various studies have demonstrated the usefulness of bevacizumab in the management of various retinal vascular pathologies like proliferative diabetic retinopathy [1-3], choroidal neovascularisation, [4-6], central retinal vein occlusion $[7,8]$, and neovascular glaucoma $[9,10]$.

\section{Case Presentation}

A 64-year-old, hypertensive female came with chief complaints of decreased vision in her right eye for 3 months.

On examination of the right eye, the vision was evaluated as counting fingers at $2 \mathrm{~m}$; the intraocular pressure was $12 \mathrm{~mm} \mathrm{Hg}$. She had a clear cornea, good pseudophakia, and peripheral posterior capsular opacification. On fundus examination, a tortuous superotemporal vessel with an area of neovascularisation near the arteriovenous crossing and a subhyaloid haemorrhage inferior to the macula were noted. A clinical diagnosis of ischaemic branch retinal vein occlusion with retinal neovascularisation and subhyaloid haemorrhage was made, which was confirmed by fluorescein angiography.

In the superotemporal quadrant, fluorescein angiography demonstrated a tortuous vessel with an area of hyperfluorescence that increased in size and intensity in the late phase, suggestive of a leaking neovascular frond near the disc. In addition, capillary nonperfusion in the adjacent area was noted (fig. 1).

The patient was informed of the potential risks and benefits of intravitreal bevacizumab, and after informed written consent, an intravitreal bevacizumab injection of $1.25 \mathrm{mg}(0.05$ $\mathrm{ml}$ ) was given to her right eye. The procedure was carried out in the operation theatre, under all aseptic precautions.

Topical $0.5 \%$ proparacaine drops were instilled. Topical $5 \%$ betadine drops were instilled in the conjunctival sac $5 \mathrm{~min}$ before the injection. Bevacizumab $1.25 \mathrm{mg}(0.05 \mathrm{ml})$ was taken into a 1-ml tuberculin syringe. Using a caliper, $3.5 \mathrm{~mm}$ temporal from the limbus was marked, and $1.25 \mathrm{mg}(0.05 \mathrm{ml})$ bevacizumab was injected intravitreally with a 27-gauge needle. Immediately after the injection, a paracentesis was done through the limbus, and the eye was padded. Acetazolamide $250 \mathrm{mg}$ was given to the patient. After $4 \mathrm{~h}$, the pad was removed, and the intraocular pressure was taken, which was normal.

The patient was instructed to administer topical moxifloxacin $0.5 \%$ eye drops 3 times a day for a period of 8 days and was told to report immediately in case of any undesired event. The patient was evaluated on the first day; 1 week later, sectoral laser treatment was done, and the patient was again reviewed 4 weeks later.

No clinical evidence of inflammation, endophthalmitis, or any other ocular toxicity was observed during the follow-up period. Further, no significant drug-related side effects were detected.

On the first day of follow-up, the vision in her right eye was maintained at counting fingers at $2 \mathrm{~m}$; the intraocular pressure was $14 \mathrm{~mm} \mathrm{Hg}$. Her right fundus revealed decreased tortuosity of the superotemporal vessel as well as a decrease in the associated neovascularisation.

After 1 week, the vision of her right eye improved to 20/125, her intraocular pressure was $14 \mathrm{~mm} \mathrm{Hg}$, and the fundus showed regression of neovascularisation. Most surprisingly, there was a marked decrease in the tortuosity and diameter of the affected retinal vascula- 
Kelkar et al.: Changes in Retinal Vascular Network after Intravitreal Bevacizumab

ture (fig. 2). Measurements of the retinal vessel diameter of the superotemporal venule before and 1 week after the injection were made using the software available on the IMAGEnet program. Image registration is possible on the program so that the same location is selected during the follow-up visits. Data are summarised in table 1.

\section{Discussion}

Costa et al. [11] have reported a similar observation with a higher dose of intravitreal injections ( $2.0 \mathrm{mg}, 0.08 \mathrm{ml}$ ) of bevacizumab. They observed that in addition to a decrease in the dye leakage from affected retinal and macular areas and within the optic disc, clear changes in the vascular retinal network morphology (diameter and tortuosity) were observed as early as 1 week after each antiangiogenic treatment. It is possible to have a reduction in the diameter and decreased venous tortuosity of the affected retinal vein in addition to regression of neovascularisation even with a bevacizumab dose of $1.25 \mathrm{mg}(0.05$ $\mathrm{ml})$, as in our case.

Vascular effects of VEGF are believed to be mediated by nitric oxide, which is a potent vasodilator. Anti-VEGF agents might impair retinal blood flow by blocking the actions of VEGF on the retinal vessels [12]. Previous reports have suggested that anti-VEGF agents might be associated with ischaemic retinal changes following intraocular use [12]. Yokoyama et al. [13] reported a patient with extensive occlusion of retinal vessels 4 weeks after intracameral bevacizumab injection for neovascular glaucoma.

This case report demonstrates that intravitreal bevacizumab might induce retinal vasoconstriction; however, larger studies are required to elucidate the potential relationship between intravitreal bevacizumab and changes in the diameter of retinal vessels and to determine its statistical significance.

\section{References}

1 Avery RL, Pearlman J, Pieramici DJ, Rabena MD, Castellarin AA, Nasir MA, et al: Intravitreal bevacizumab (Avastin) in the treatment of proliferative diabetic retinopathy. Ophthalmology 2006;10:1695-1705.

$>2$ Jeon S, Lee WK: Effect of intravitreal bevacizumab on diabetic macular edema with hard exudates. Clin Ophthalmol 2014;8:1479-1486.

-3 Fernando Arevalo J: Intravitreal bevacizumab as anti-vascular endothelial growth factor in the management of complications of proliferative diabetic retinopathy. Med Hypothesis Discov Innov Ophthalmol 2013;2:2024.

-4 Rosenfeld PJ, Moshfeghi AA, Puliafito CA: Optical coherence tomography findings after an intravitreal injection of bevacizumab (Avastin) for neovascular age-related macular degeneration. Ophthalmic Surg Lasers Imaging 2005;36:331-335.

-5 Cheema RA, Mushtaq J, Cheema MA: Intravitreal bevacizumab as a primary treatment for idiopathic choroidal neovascularisation. Middle East Afr J Ophthalmol 2011;18:220-223.

-6 Solomon SD, Lindsley K, Vedula SS, Krzystolik MG, Hawkins BS: Anti-vascular endothelial growth factor for neovascular age-related macular degeneration. Cochrane Database Syst Rev 2014;8:CD005139.

-7 Rosenfeld PJ, Fung AE, Puliafito CA: Optical coherence tomography findings after an intravitreal injection of bevacizumab (Avastin) for macular edema from central vein occlusion. Ophthalmic Surg Lasers Imaging 2005;36:336-339.

8 Braithwaite T, Nanji AA, Lindsley K, Greenberg PB: Anti-vascular endothelial growth factor for macular edema secondary to central retinal vein occlusion. Cochrane Database Syst Rev 2014;5:CD007325.

-9 Kahook MY, Schuman JS, Noecker RJ: Intravitreal bevacizumab in a patient with neovascular glaucoma. Ophthalmic Surg Lasers Imaging 2006;37:144-146.

10 Simha A, Braganza A, Abraham L, Samuel P, Lindsley K: Anti-vascular endothelial growth factor for neovascular glaucoma. Cochrane Database Syst Rev 2013;10:CD007920.

-11 Costa RA, Jorge R, Calucci D, Melo LA Jr, Cardillo JA, Scott IU: Intravitreal bevacizumab (Avastin) for central and hemicentral retinal vein occlusions: IBeVO study. Retina 2007;27:141-149. 
Case Reports in

Ophthalmology

\begin{tabular}{l|l}
\hline Case Rep Ophthalmol 2014;5:411-415 \\
\hline DOI: $10.1159 / 000368343$ & $\begin{array}{l}\text { C 2014 S. Karger AG, Basel } \\
\text { www.karger.com/cop }\end{array}$ \\
\hline
\end{tabular}

Kelkar et al.: Changes in Retinal Vascular Network after Intravitreal Bevacizumab

12 Tatlipinar S, Dinç UA, Yenerel NM, Görgün E: Short-term effects of a single intravitreal bevacizumab injection on retinal vessel caliber. Clin Exp Optom 2012;95:94-98.

13 Yokoyama K, Choshi T, Kimoto K, Shinoda K, Nakatsuka K: Retinal circulatory disturbances following intracameral bevacizumab for neovascular glaucoma. Acta Ophthalmol 2008;86:927-928.

Table 1. Measurements of retinal vessel diameters before and after the injection using IMAGEnet software, performed by the same observer (to eliminate inter-observer bias)

\begin{tabular}{lll}
\hline & $\begin{array}{l}\text { Diameter before } \\
\text { injection, } \mu \mathrm{m}\end{array}$ & $\begin{array}{l}\text { Diameter } 1 \text { week after } \\
\text { injection, } \mu \mathrm{m}\end{array}$ \\
\hline Position A & 162 & 48 \\
Position B & 148 & 37 \\
\hline
\end{tabular}

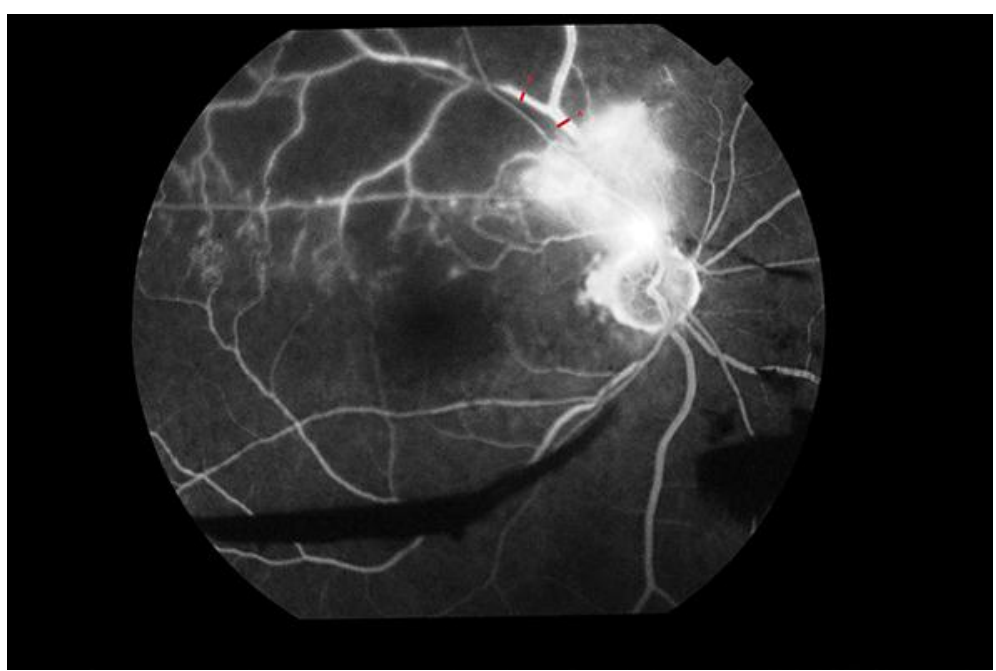

Fig. 1. Pre-injection fundus fluorescein angiography findings. The leaking neovascular frond and dilated tortuous superotemporal vessel are shown. 
Case Reports in

Ophthalmology
Case Rep Ophthalmol 2014;5:411-415

DOI: $10.1159 / 000368343$

Kelkar et al: Changes in Retinal Vascular Network after Intravitreal Bevacizumab

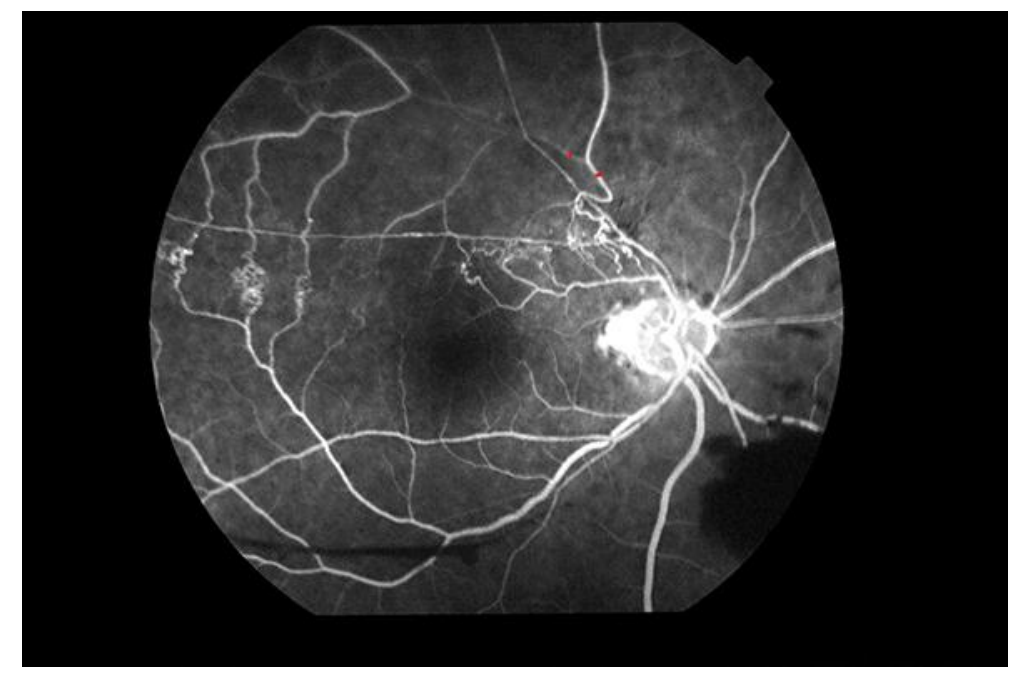

Fig. 2. Post-injection fundus fluorescein angiography findings. A decrease in the dye leakage from affected retinal neovcascularisation and a clear reduction in the retinal vessel morphology (diameter and tortuosity) are shown. 